\title{
Development of a primary mouse intestinal epithelial cell monolayer culture system to evaluate factors that modulate lgA transcytosis
}

\author{
C Moon ${ }^{1}$, KL VanDussen ${ }^{1}, \mathrm{H}_{\text {Miyoshi }}{ }^{1}$ and TS Stappenbeck ${ }^{1}$
}

There is significant interest in the use of primary intestinal epithelial cells in monolayer culture to model intestinal biology. However, it has proven to be challenging to create functional, differentiated monolayers using current culture methods, likely due to the difficulty in expanding these cells. Here, we adapted our recently developed method for the culture of intestinal epithelial spheroids to establish primary epithelial cell monolayers from the colon of multiple genetic mouse strains. These monolayers contained differentiated epithelial cells that displayed robust transepithelial electrical resistance. We then functionally tested them by examining immunoglobulin A (IgA) transcytosis across Transwells. IgA transcytosis required induction of polymeric lg receptor (plgR) expression, which could be stimulated by a combination of lipopolysaccharide and inhibition of $\gamma$-secretase. In agreement with previous studies using immortalized cell lines, we found that tumor necrosis factor- $\alpha$, interleukin (IL)-1 $\beta$, IL-17, and heat-killed microbes also stimulated plgR expression and IgA transcytosis. We used wild-type and knockout cells to establish that among these cytokines, IL-17 was the most potent inducer of plgR expression/lgA transcytosis. Interferon- $\gamma$, however, did not induce plgR expression, and instead led to cell death. This new method will allow the use of primary cells for studies of intestinal physiology.

\section{INTRODUCTION}

The study of intestinal epithelial biology has been made feasible through advances in the field of gastroenterology during the past few decades. Some of these technical advances have included the development of genetically and microbiologically defined animal models, animal models of injury and repair, and immortalized epithelial cell lines for in vitro studies. Most recently, the ability to propagate primary intestinal epithelial cells in vitro has greatly advanced the field. ${ }^{1,2}$

Before the ability to grow primary intestinal epithelial cells, colon cancer cell lines have been widely used to model physiologic and cell biologic intestinal processes in vitro. Studies using these lines have provided initial insights into epithelial biology in many areas. For example, Caco-2, HT-29, and T84 cells can form monolayers of differentiated cells. ${ }^{3-5}$ However, colon cancer cell lines have many well-recognized limitations including prolonged time to attain mature monolayers ( $\sim 20$ days in culture for some lines), aneuploidy, and the presence of numerous undefined DNA mutations. Additional alternatives to human cancer cell lines have been developed and include the use of virally-transformed intestinal epithelial cells such as rat IEC-18 cells, or non-intestinal epithelial cells such as MDCK (Madin-Darby canine kidney) cells, but these systems also have limitations. ${ }^{6,7}$

One advantage these various cell lines have over the current primary intestinal epithelial cell culture method is their ability to form polarized monolayers in Transwells. This has provided the means to study many epithelial cell processes including interactions with other cell types, interactions with microbes, drug absorption, and intracellular trafficking. ${ }^{6,8,9}$ One such intestinal epithelial cell process that has been well-dissected and characterized using these cell lines is immunoglobulin A (IgA) transcytosis via the polymeric Ig receptor (pIgR). ${ }^{10-12}$

The majority (75\%) of the total Ig produced in the body is made in the intestine, where $\operatorname{IgA}$ is the predominant isotype produced. ${ }^{13}$ Humans secrete $\sim 3 \mathrm{~g}$ of IgA in the intestine per day. Although IgA can be found as a monomer in the serum,

${ }^{1}$ Department of Pathology and Immunology, Washington University School of Medicine, St Louis, Missouri, USA. Correspondence: TS Stappenbeck (stappenb@pathology.wustl.edu)

Received 29 August 2013; accepted 14 October 2013; published online 13 November 2013. doi:10.1038/mi.2013.98 
the polymeric form (pIgA) connected by the J chain (IgJ) is the predominant form at mucosal sites. ${ }^{14}$

Plasma cells produce and secrete pIgA locally in the lamina propria. For the IgA to enter the intestinal lumen, pIgA must bind to its receptor $\mathrm{pIgR},{ }^{15,16}$ which is expressed basolaterally on epithelial cells. The pIgA-bound pIgR is then endocytosed in clathrin-coated vesicles and transcytosed across the cell through several distinct compartments to the apical surface. ${ }^{10,12,17}$ At (or near) the cell surface, as of yet unidentified enzymes cleave the receptor, releasing the PIgA still bound to the extracellular portion of pIgR (known as the secretory component, or SC). This secretory IgA, protected by the J chain as well as the SC, is more resistant to cleavage by intestinal proteases. $^{18}$

Several studies have shown that the expression of $\mathrm{pIgR}$ in the intestinal epithelium is regulated by bacterial stimuli. Germ-free mice have a threefold increase in pIgR expression in the ileum upon monocolonization with Bacteroides thetaiotamicron. ${ }^{19}$ In vitro studies have shown that stimulation of HT-29 cells with microbial factors (such as lipopolysaccharide (LPS), butyrate, and double-stranded RNA) or heat-killed bacteria can upregulate pIgR expression. ${ }^{20,21}$ Proinflammatory cytokines produced in response to microbial stimuli, such as interferon- $\gamma$ (IFN $\gamma)$, tumor necrosis factor- $\alpha$ (TNF $\alpha)$, interleukin (IL)-1, and most recently, IL-17 have also been shown to increase $\mathrm{pIgR}$ expression in vitro. ${ }^{10,11,22-26}$

Here, for the first time, we established a system to grow primary intestinal epithelial cell monolayers. This will assist in the study of intestinal epithelial cell processes in vitro using primary cells. We chose to focus on the process of $\operatorname{IgA}$ transcytosis using this system. We were able to adapt the previously established three-dimensional (3D) primary intestinal epithelial stem cell culture system into a 2D monolayer in a Transwell. These cells are able to express pIgR after stimulation with LPS, and transcytose IgA across the monolayer. TNF $\alpha$, IL-1 $\beta$, and IL-17 were able to induce PIgR expression and IgA transcytosis in a dose-dependent manner. Importantly, perhaps demonstrating a distinction with previous methodologies using immortalized cell lines, IFN $\gamma$ did not enhance pIgR expression. Heat-killed bacteria were also able to stimulate these processes to differing extents. Finally, this system will be readily adaptable for the use with available genetically modified mice to study different genes of interest: primary intestinal epithelial cells from $p I g R^{-/-}$mice do not show IgA transcytosis into the supernatants, whereas cells from $\mathrm{Tlr} 4^{-/-}$mice have reduced pIgR expression and IgA transcytosis after LPS stimulation compared with wild-type cells.

\section{RESULTS}

\section{Developing a Transwell system for mouse primary} intestinal epithelial cells

A critical roadblock to understanding intestinal physiology has been the lack of an experimental system to model primary intestinal epithelial cells as a polarized, confluent monolayer. The use of primary cells is of interest owing to the differentiation potential of these cells in vitro ${ }^{1}$ as well as the need to evaluate cells from genetically modified mice. It has been challenging to adapt primary intestinal epithelial cells to Transwell culture as monolayers because this technique requires a substantial number of viable cells.

We have solved this problem using an in vitro experimental system that allowed for significant expansion of intestinal epithelial stem/progenitor cells. ${ }^{2}$ To obtain cells for a single Transwell, we harvested colonic spheroids from three wells (400-500 spheroids per well) of a 24-well plate that were cultured as spheroids for 3 days in Matrigel using 50\% L-WRN (L cells expressing $W n t 3 a, R$-spondin 3 , and Noggin) conditioned media $(\mathrm{CM})$. This produced $\sim 5 \times 10^{5}$ cells that were seeded onto a single $0.33 \mathrm{~cm}^{2}$ Transwell insert of a 24-well plate. Typically this cell input created a monolayer of $\sim 2.5 \times 10^{5}$ cells. At the time of seeding cells in Transwells, we used 50\% L-WRN CM that also contained $10 \mu \mathrm{M}$ of the ROCK inhibitor Y-27632 (Figure 1a). The media were maintained for 1 day after seeding.

On day 1 after seeding, the 50\% CM was replaced with $0 \%$ $\mathrm{CM}$ supplemented with or without specific treatments that were designed to facilitate the study of IgA transcytosis. The treatment included a combination of the $\gamma$-secretase inhibitor DAPT ( $N$-[ $N$-(3,5-difluorophenacetyl-L-alanyl)]-S-phenylglycine $t$-butyl ester) to differentiate the cells ${ }^{27,28}$ and LPS to induce the expression of pIgR (which is known to be regulated by microbial and/or cytokine signaling). ${ }^{19}$ The cells were treated for 2 days in this media before evaluation for differentiation by histology and gene expression analysis, as well as functional assays such as IgA transcytosis.

We next evaluated the effects of DAPT + LPS on differentiation and lineage allocation of primary epithelial monolayers. Cells were fixed on a Transwell membrane, which was then cut out of the insert and processed for paraffin embedding. Histologic sections were cut and stained with hematoxylin and eosin. We observed that both untreated and DAPT + LPS-treated cells showed a single layer of cells overlying the Transwell membrane (Figure 1b). To confirm that differentiation of enterocytes occurred both with and without DAPT + LPS treatments, we performed immunostaining using antisera against Villin1 and ZO-1. Villin1 marks the microvilli ${ }^{29}$ and ZO-1 is a tight junction marker. ${ }^{30}$ In addition, both of these proteins showed appropriate apical localization throughout the monolayer and this pattern was present regardless of treatment. We also found that a basolateral marker, CD138, showed appropriate localization in Transwell cultures (Supplementary Figure 1a online). Taken together, the localization of these markers is consistent with polarized epithelial cells. We stained for markers of additional colonic epithelial lineages including enteroendocrine cells (chromogranin $\mathrm{A}^{31}$ ) and goblet cells (lectin UEA-1 ${ }^{32}$ ). Whole mount images of immunostained Transwells showed that both of these cell types were present in DAPT + LPS-treated monolayers with lower fractional representation than absorptive enterocytes (Supplementary Figure $\mathbf{1 b}, \mathbf{c})$. This lineage allocation is similar to what is observed in vivo for the surface epithelium of the mouse colon (Supplementary Figure 1d-h). 

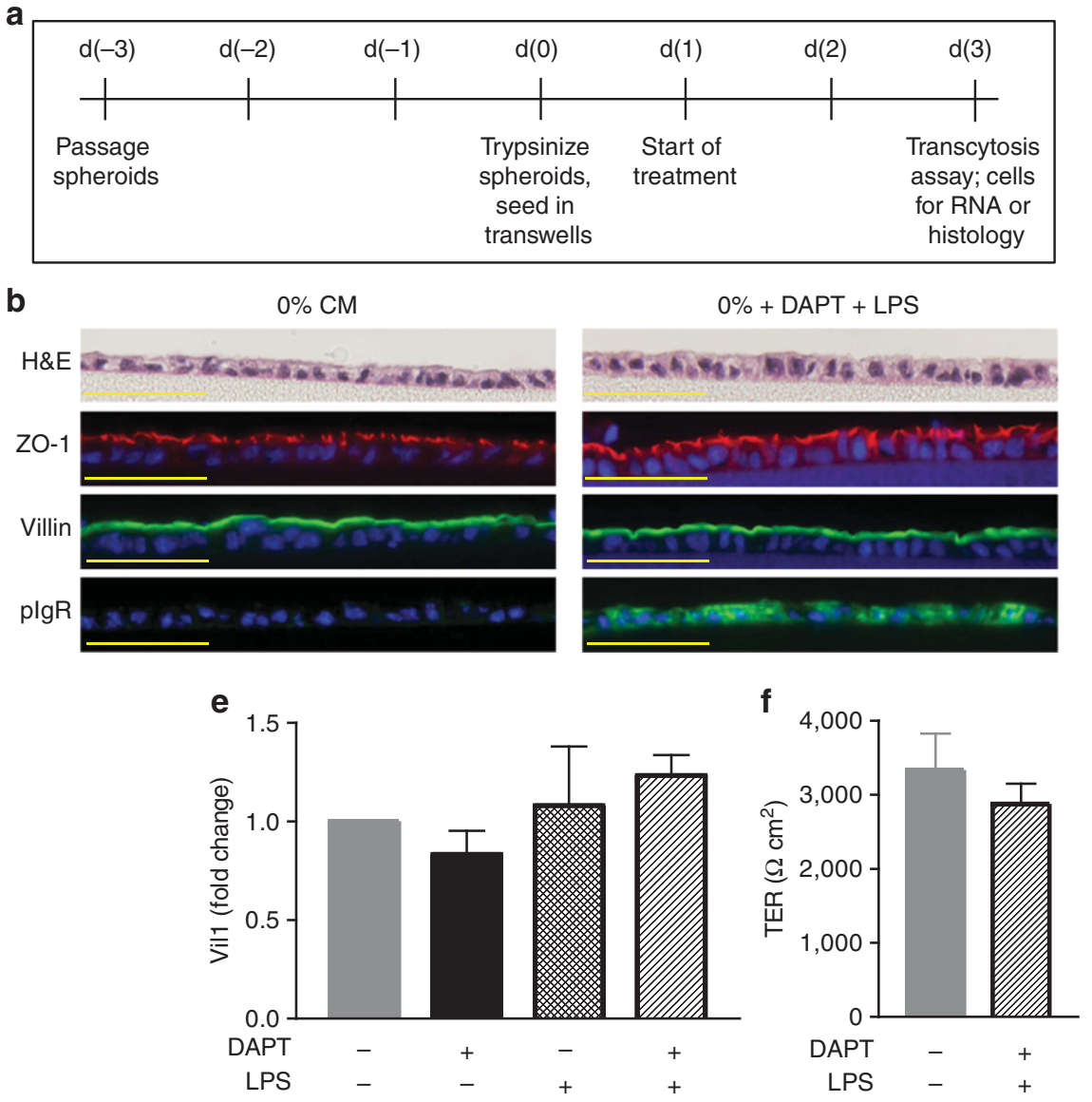
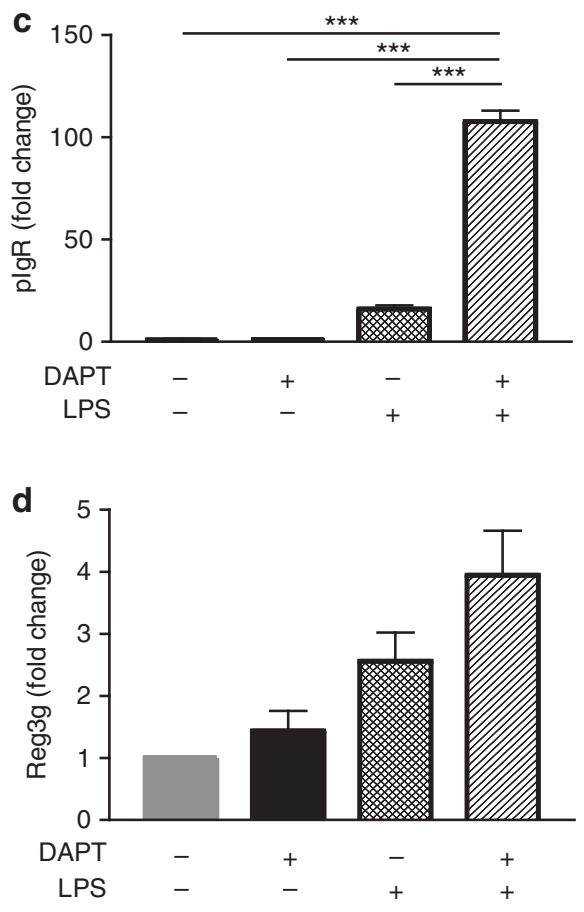

Figure 1 Developing a transwell system using mouse primary intestinal epithelial cells. (a) Schematic of timeline for Transwell experiments. Wild-type cells were treated with $\pm 10 \mu \mathrm{m}$ DAPT ( $N$-[N-(3,5-difluorophenacetyl-L-alanyl)]-S-phenylglycine $t$-butyl ester) $\pm 1 \mu \mathrm{g} \mathrm{ml}^{-1}$ lipopolysaccharide (LPS) and were analyzed on day 3 after seeding. (b) Cells were fixed and paraffin embedded on the transwell membranes. Sections were cut and stained with the following: hematoxylin and eosin (H\&E), anti-ZO-1, anti-Villin, and anti-polymeric immunoglobulin receptor (plgR). Bar $=50 \mu m$. Gene expression analysis was performed by quantitative real-time polymerase chain reaction for (c) plgR, (d) Reg3g, and (e) Villin1 (Vil1). All samples were normalized to glyceraldehyde 3-phosphate dehydrogenase mRNA, and data were presented as fold change relative to untreated ( $0 \%$ conditioned media) cells (mean \pm s.e.m.; $n \geq 3$ per condition). One-way analysis of variance: (c) $\mathrm{F}=96.02, P<0.0001 ;(\mathbf{d}) \mathrm{F}=3.441, P<0.0376$; (e) $\mathrm{F}=1.085, P<0.3762$. ${ }^{* *} P<0.001$ by Bonferroni's multiple comparison test. (f) Transepithelial electrical resistance was measured on day 3. The (resistance $\times$ area) is shown for each condition (mean \pm s.e.m., $n=6$ per group). Statistical analysis by Student's $t$-test showed no significant difference between the two groups $(P<0.4362)$.

To adapt this experimental system for the study of $\operatorname{IgA}$ transcytosis, we evaluated the expression of pIgR both in vivo and in vitro. The colonic epithelium, including surface epithelial cells, expressed pIgR in vivo (Supplementary Figure 1i,j). In vitro, pIgR could be induced in epithelial monolayers that were treated with DAPT + LPS, as shown by immunostaining (Figure 1b). To quantify the relative effects of DAPT and LPS on pIgR expression, we performed quantitative real-time polymerase chain reaction of mRNAs isolated from epithelial cells grown on Transwells for 3 days. The addition of DAPT + LPS stimulated a robust increase in pIgR mRNA expression compared with untreated cells ( $\sim 100$-fold increase) (Figure 1c). This finding corroborated the effects of DAPT + LPS on protein expression as determined by immunostaining (Figure 1b). Single treatment with either LPS or DAPT did not stimulate PIgR mRNA expression to the extent that was achieved by the combination of these factors (Figure 1c). As a positive control for LPS treatment, expression of RegIII $\gamma^{33}$ was increased after DAPT + LPS treatment (Figure 1d). As a negative control, Villin1 expression (which is not microbially regulated in vivo ${ }^{34}$ ) was similar in all groups of treated and untreated cells (Figure 1e). Thus, we were able to show that wild-type primary colonic epithelial cells on Transwells were responsive to DAPT + LPS.

To perform IgA transcytosis experiments, a complete monolayer of cells is required. To demonstrate that the seeded cells formed a functional monolayer, we measured transepithelial electrical resistance (TER) in the Transwells on day 3 (Figure 1f). For this experiment, we used cells at a density of $\sim 2.5 \times 10^{5}$ cells per $0.33 \mathrm{~cm}^{2}$. The average TER of untreated cells was $3,333 \Omega \mathrm{cm}^{2}$. The TER of DAPT + LPS-treated cells was similar to the TER of untreated cells $\left(2,877 \Omega \mathrm{cm}^{2}\right)$. 


\section{Developing an IgA transcytosis assay using primary mouse Transwell cultures}

One of the critical functions of the intestinal epithelium is the transcytosis of IgA from the lamina propria to the lumen of the intestine. This process involves pIgR trafficking across the intestinal epithelium that can occur at a slower rate in the absence of $\operatorname{IgA} .^{35}$ To determine if the primary intestinal epithelial monolayers were capable of IgA transcytosis, we developed an assay utilizing these cells. At day 3 after plating on Transwell inserts, the cells were washed and placed in wells containing normal mouse IgA in the lower compartment. This media is in contact with the basolateral surface of the epithelial monolayer. Media alone were added to the upper compartment (apical surface). The cells were incubated at $37^{\circ} \mathrm{C}$ for different periods of time to allow for receptor binding and transcytosis to occur before the media in the upper compartment was sampled for analysis by enzyme-linked immunosorbent assay (ELISA). Colonic cells isolated from $\mathrm{pIgR} \mathrm{R}^{-1-}$ mice were used as a negative control for all transcytosis experiments.

Consistent with the pIgR mRNA expression data, cells treated with DAPT + LPS showed measurable IgA in the apical media, whereas the other three groups (untreated, DAPT alone, and LPS alone) had levels at or below the limit of detection (Figure 2a). Apical media from $\mathrm{PIgR}{ }^{-/-}$cells did not contain
IgA regardless of treatment. This genetic control indicated that IgA is actively transported through epithelial cells and does not use paracellular transport.

To determine the optimal conditions for transcytosis experiments, we performed IgA dose-response curve and time-course experiments using DAPT + LPS-treated cells. One hour after the addition of IgA to the basal compartment, no IgA was detected in the apical media (Figure 2b). Therefore, $1 \mathrm{~h}$ was not sufficient for IgA in the basal compartment to bind PIgR and transcytose across cells to the apical compartment. This result also showed that the monolayer was intact and thus did not allow the IgA to diffuse freely into the apical media. Because of this result, we utilized the 1-h time point as an additional internal control in all subsequent experiments. Additional time points were taken $3 \mathrm{~h}$ ( $4 \mathrm{~h}$ after the addition of IgA) and $6 \mathrm{~h}$ later $(10 \mathrm{~h}$ after the addition of IgA). Both of these time points showed progressively higher levels of IgA in the apical media (Figure 2b). In subsequent experiments, all three of these time points were evaluated.

In choosing the optimal dose of $\operatorname{Ig} \mathrm{A}$, the amount of $\operatorname{Ig} \mathrm{A}$ in the apical compartment at 3- and 6-h time point needed to be in linear range of the ELISA. We initially used normal mouse IgA from Santa Cruz Biotechnology at a dose of $40 \mu \mathrm{l}$ per well (Figure 2c). In later experiments, we used normal mouse IgA

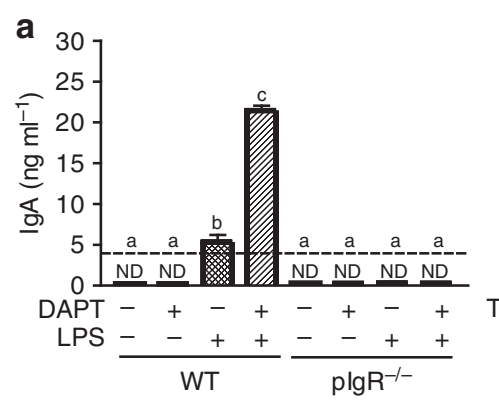

d

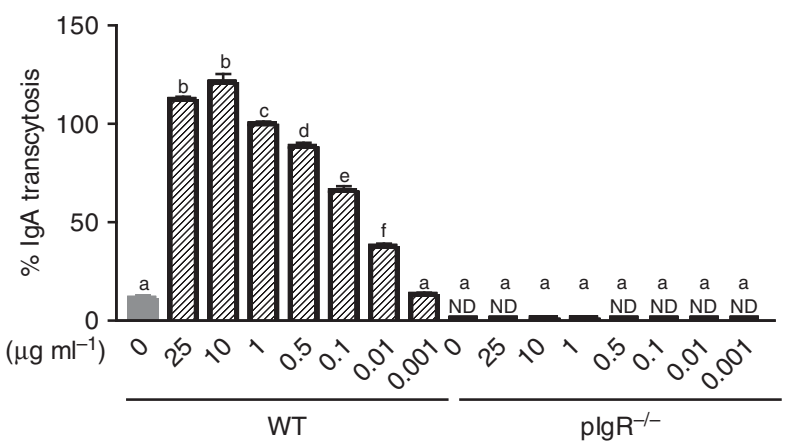

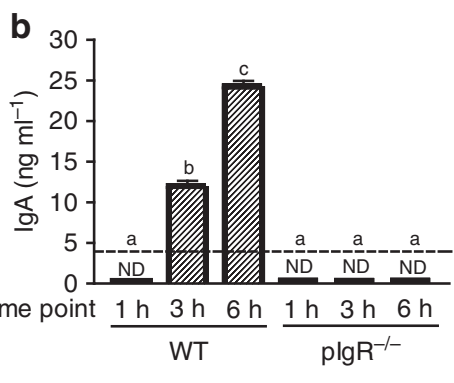
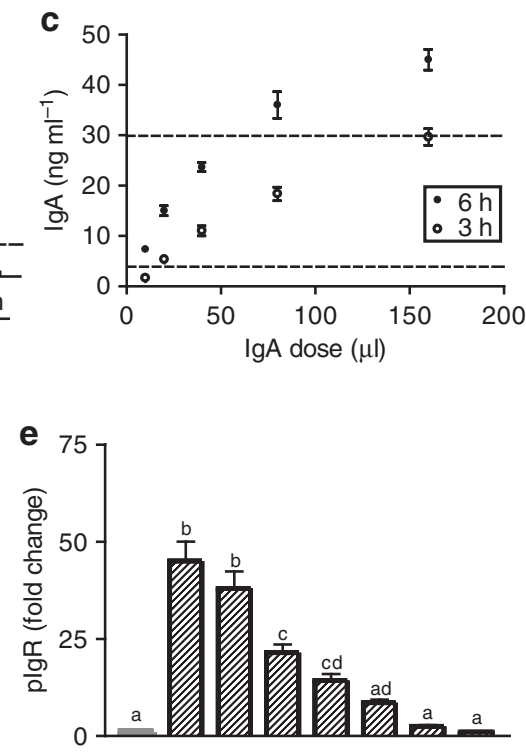

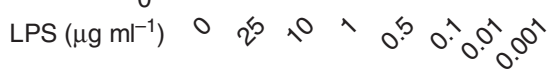

Figure 2 Developing an immunoglobulin A (IgA) transcytosis assay. (a) Wild-type (WT) and plgR $R^{-/-}$cells were seeded in Transwells and treated

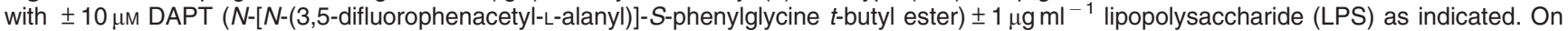
day 3 after seeding, $40 \mu \mathrm{l}$ of normal mouse IgA (Santa Cruz Biotechnology) was added to the lower compartment of the Transwells, and supernatants from the upper compartment were taken at $6 \mathrm{~h}$ for the detection of IgA by enzyme-linked immunosorbent assay (ELISA). (b) Time-course and (c) IgA

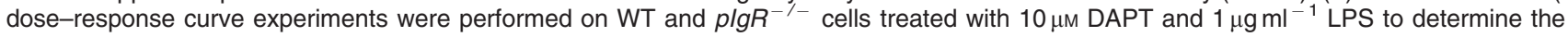
optimal conditions for future experiments. An LPS dose-response curve was performed to determine whether (d) IgA transcytosis and (e) plgR expression were dose-dependent. All LPS-treated cells were also treated with $10 \mu \mathrm{m}$ DAPT. For IgA transcytosis, results from the ELISA were normalized to the $1 \mathrm{\mu g} \mathrm{ml}^{-1} \mathrm{LPS}$ treatment group (=100\%). Gene expression analysis by quantitative real-time polymerase chain reaction for plgR was performed by normalizing to glyceraldehyde 3-phosphate dehydrogenase, and data are presented as fold change relative to untreated cells. The dotted lines represent the limit of detection by the ELISA. All values are indicated as mean \pm s.e.m. One-way analysis of variance: (a) $\mathrm{F}=573.3, P<0.0001$, $n \geq 3$ per group; (b) $\mathrm{F}=539.2, P<0.0001, n \geq 12$ per group; (d) $\mathrm{F}=675.7, P<0.0001, n \geq 3$ per group; and (e) $\mathrm{F}=46.22, P<0.0001, n \geq 6$ per group. Means with different letters are significantly different by Bonferroni's multiple comparison test. ND, not detected; plgR, polymeric Ig receptor. 
from $\mathrm{BD}$ Pharmingen at a comparable dose, which allowed for a more precise measurement of IgA concentration and decreased variability between experiments (Supplementary Figure 2). For this source of IgA, we were able to calculate the $\operatorname{IgA}$ concentration used to $5 \mu \mathrm{g} \mathrm{ml}^{-1}$, or a total of $3 \mu \mathrm{g}$ per well.

As it was unclear how sensitive primary wild-type colonic epithelial cells were to LPS, we performed a dose-response curve for LPS using both IgA transcytosis and pIgR expression as readouts (Figure 2d and e). Both transcytosis and pIgR mRNA expression responded in a dose-dependent manner. In all subsequent experiments, we used $1 \mu \mathrm{g} \mathrm{ml}^{-1}$ LPS as this was in linear range of the response of wild-type cells.

Although LPS has been used as a standard in the field to induce efficiently pIgR expression in different cell types, there is growing interest in the study of the effects of specific microbes in the intestine and how they stimulate IgA..$^{20,21,36-38}$ To model an example of such host-microbial interactions in vitro, cells were treated with heat-killed Escherichia coli to analyze its ability to induce IgA transcytosis and pIgR expression (Figure 3a and $\mathbf{b}$ ). A dose equivalent to $10^{7}$ colony-forming unit per $\mathrm{ml}$ E. coli was found to induce similar levels of IgA transcytosis and $\mathrm{pIgR}$ expression as that demonstrated for $1 \mu \mathrm{g} \mathrm{ml}^{-1}$ LPS.

\section{Cell density affects IgA transcytosis and plgR expression in Transwell cultures}

We noticed that there was occasional experiment-to-experiment variability of the amount of IgA transcytosed. Further scrutiny of the Transwells utilized in these experiments led us to hypothesize that the cellular density has a role in the level of IgA transcytosis in vitro. To test this idea, we performed twofold serial dilutions of the cells seeded in the Transwells (Figure 4a). Both the undiluted (using $\sim 5 \times 10^{5}$ cells as above) and a 1:2 dilution showed similar amounts of transcytosed IgA. However, a 1:4 dilution reproducibly showed significantly less transcytosed IgA. Furthermore, apical media collected from a 1:8 dilution showed IgA at levels below the limit of detection. This result suggested that there was an intact monolayer at this cell density but no detectable IgA was transcytosed. At a 1:16 dilution, we could not reproducibly achieve a monolayer, as in some experiments, IgA was readily detected in the apical compartment at levels similar to the basolateral chamber. TER measurements corroborated these findings. Higher cell densities all showed resistance values of $>2,500 \Omega \mathrm{cm}^{2}$ (Supplementary Figure 3). The TER for the 1:8 cell dilution was more variable, with average values of $\sim 1,240 \Omega \mathrm{cm}^{2}$. The TER for the 1:16 dilution was near baseline values.
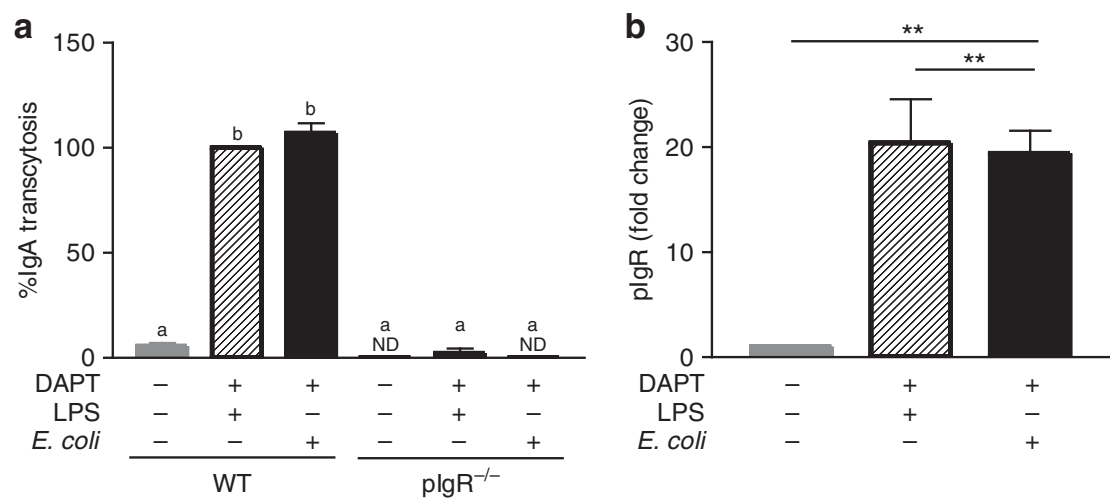

Figure 3 Immunoglobulin A (IgA) transcytosis and polymeric Ig receptor (plgR) expression are induced by heat-killed bacteria. Wild-type (WT) and $p l g R^{-/-}$cells were seeded in Transwells and treated with $10 \mu \mathrm{m}$ DAPT ( $N$-[N-(3,5-difluorophenacetyl-L-alanyl)]-S-phenylglycine $t$-butyl ester) and $1 \mathrm{\mu g} \mathrm{ml}^{-1}$ lipopolysaccharide (LPS) or $10^{7}$ colony-forming unit per $\mathrm{ml}$ heat-killed $E$. coli as indicated. (a) IgA transcytosis was analyzed by enzyme-linked immunosorbent assay, and results were normalized to the WT + DAPT + LPS group (=100\%). (b) Gene expression analysis by quantitative real-time polymerase chain reaction of plgR was performed and all samples were normalized to glyceraldehyde 3-phosphate dehydrogenase. Data are presented as fold change relative to untreated ( $0 \%$ conditioned media) cells. All values are indicated as mean $\pm s . e . m$. One-way analysis of variance: (a) $\mathrm{F}=426.2, P<0.0001, n \geq 6$ per group, means with different letters are significantly different by Bonferroni's multiple comparison test; (b) $\mathrm{F}=11.47, P<0.0008, n \geq 5$ per group, ${ }^{\star *} P<0.01$ by Bonferroni's multiple comparison test.

Figure 4 Cell density affects differentiation state of intestinal epithelial cells in transwells. Twofold serial dilutions of wild-type cells were seeded into Transwells and treated with $10 \mu \mathrm{m}$ DAPT ( $N$-[N-(3,5-difluorophenacetyl-L-alanyl)]-S-phenylglycine $t$-butyl ester) and $1 \mu \mathrm{g} \mathrm{ml}{ }^{-1}$ lipopolysaccharide (LPS). (a) Immunoglobulin A (IgA) transcytosis was performed on day 3 after seeding, and measurement of IgA in the supernatants at the 6-h time point is shown. (b and c) Cells were fixed and stained on the (c) Transwell membranes with anti-polymeric lg receptor plgR (green) and bis-benzamide dye (blue). Bar $=200 \mu \mathrm{m}$. (b) Quantification of cell density of cells on Transwells was performed using ImageJ software. Gene expression analysis was performed by quantitative real-time polymerase chain reaction for (d) plgR, (e) Muc2, (f) Atoh1, and (g) villin1 (Vil1). All samples were normalized to glyceraldehyde 3-phosphate dehydrogenase, and data are presented as fold change relative to untreated $(0 \%$ conditioned media) cells. The dotted lines represent the limit of detection by the enzyme-linked immunosorbent assay. All values are indicated as mean \pm s.e.m. One-way analysis of variance: (a) $\mathrm{F}=53.11, P<0.0001, n \geq 6$ per group; (b) $\mathrm{F}=183.2, P<0.0001, n \geq 15$ per group;

(d) $\mathrm{F}=39.02, P<0.0001, n \geq 3$ per group; (e) $\mathrm{F}=11.07, P<0.0001, n \geq 3$ per group; (f) $\mathrm{F}=3.436, P<0.0183, n \geq 3$ per group; and (g) $\mathrm{F}=2.186$, $P<0.0894, n \geq 3$ per group. Means with different letters are significantly different by Bonferroni's multiple comparison test. 

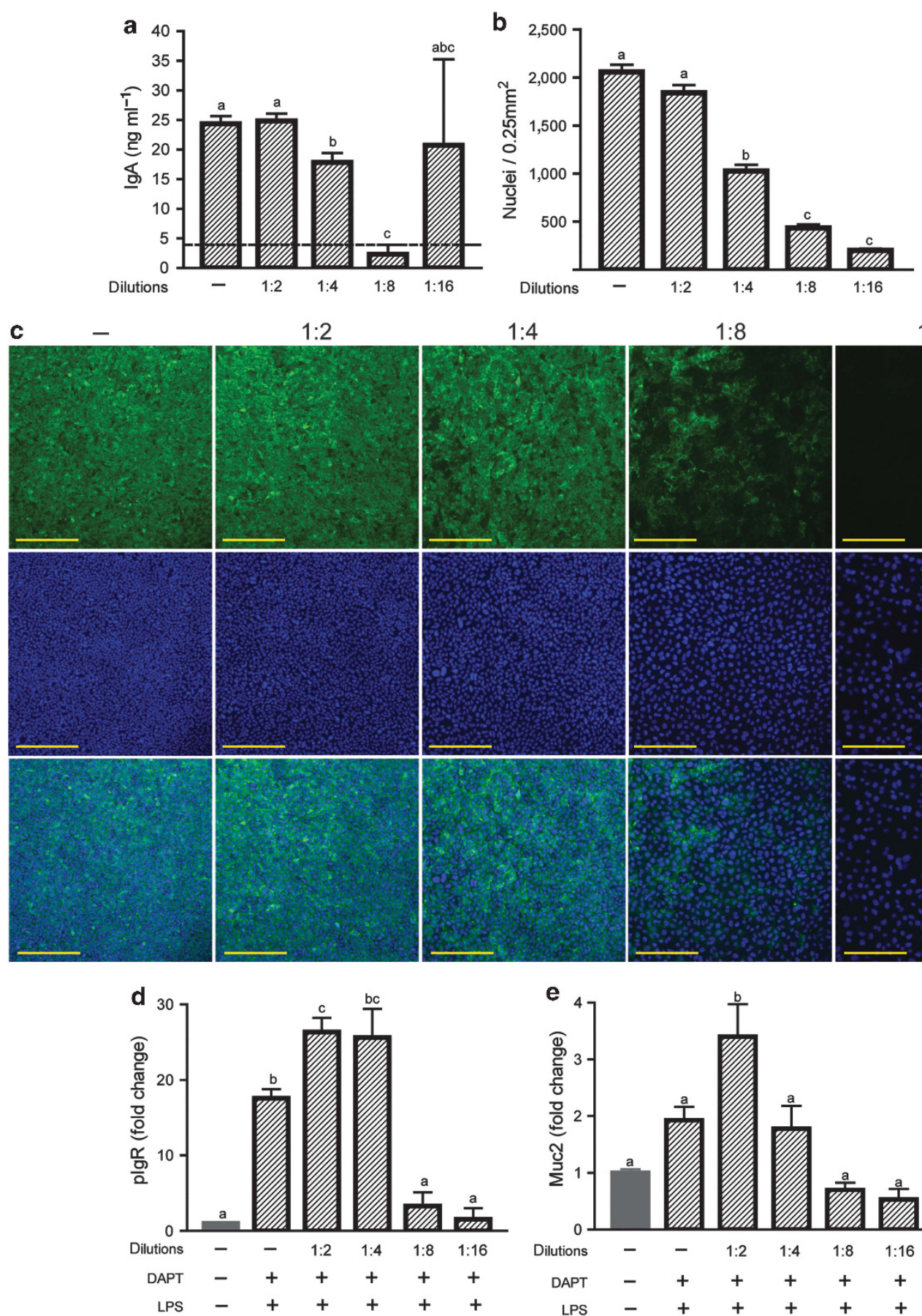

$1: 4$

$1: 8$

1:16
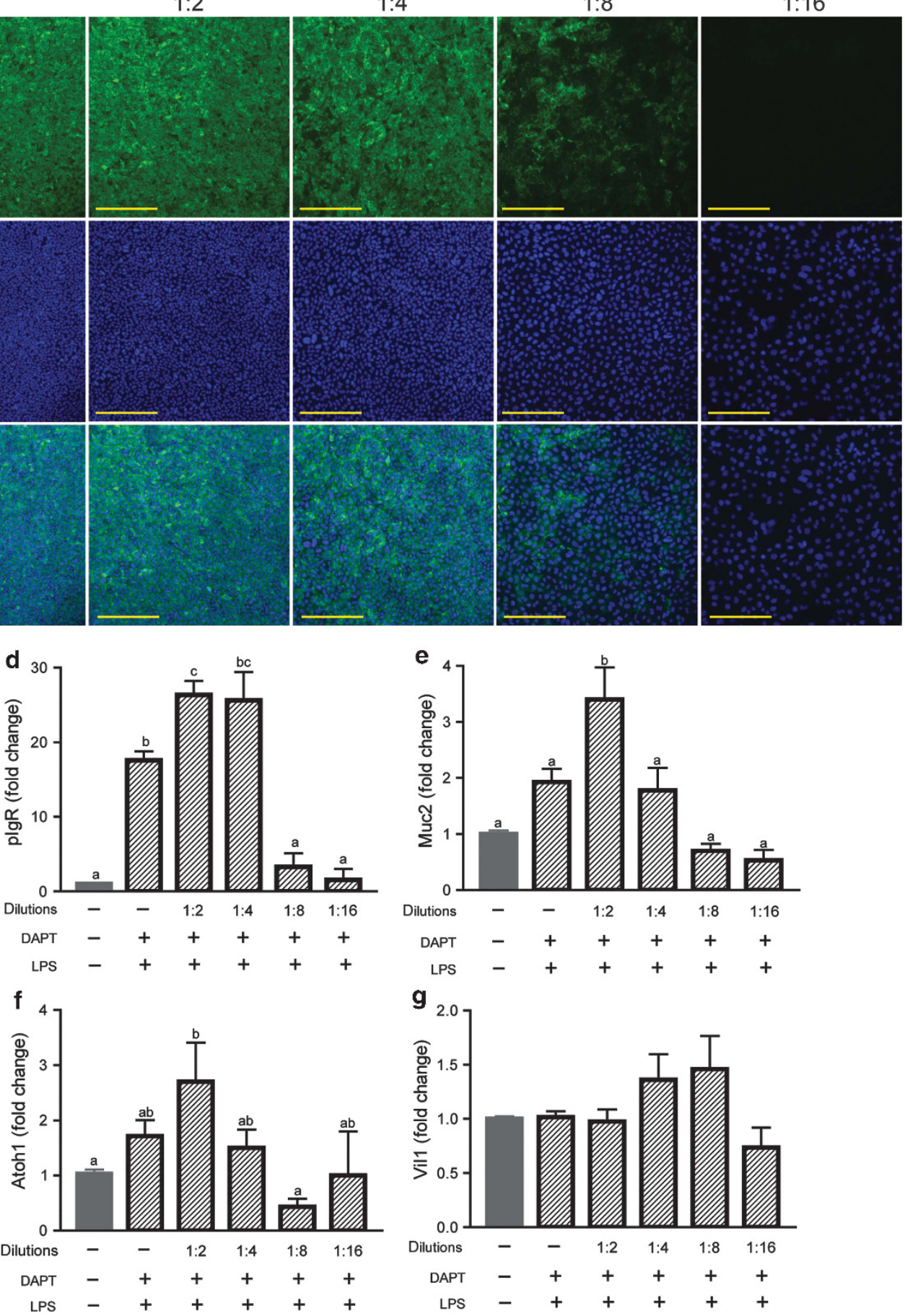
The cell density was quantified for each dilution by nuclei counts of whole-mount images of bis-benzimide-stained Transwell membranes (Figure $\mathbf{4 b}$ and $\mathbf{c}$ ). A 1:2 dilution of input cells resulted in only a small change in the number of seeded cells on the Transwell, indicating that maximum cell numbers were seeded at these two input densities. Each successive twofold dilution showed a $\sim 2$-fold decrease in cell density. We next tested whether the correlation of cell density to IgA transcytosis was due to cell number and/or pIgR expression. Costaining of cells with anti-pIgR antisera showed detectable staining in the majority of cells in Transwells with higher cell densities (no dilution, 1:2 and 1:4). We observed a substantial decrease in the number of cells that were positive for pIgR in 1:8 dilution samples. There was no detectable staining for pIgR in the 1:16 dilution samples. To confirm this observation, we performed gene expression analysis for $\mathrm{pIgR}$ at each dilution (Figure 4d). The highest relative expression of pIgR was observed at the 1:2 and 1:4 dilution samples. We observed a threshold effect whereby pIgR expression was substantially lower in the 1:8 and 1:16 dilution samples. Our interpretation is that the decrease in IgA transcytosis that occurred between the 1:2 and the 1:4 dilutions is likely due to changes in cell density, whereas the decrease in $\operatorname{IgA}$ trancytosis in the 1:8 dilution is likely further driven by diminished pIgR expression. One other possibility is that global differentiation is altered by decreased density. We found that markers of secretory lineages (Muc2 and Atoh1) were diminished in a density-dependent manner, whereas a general marker of epithelial cells (Villin1) was not altered (Figure $4 \mathbf{e}-\mathbf{g}$ ).

\section{Cytokines induce plgR expression and IgA transcytosis in the primary Transwell cultures}

Several different cytokines were previously shown to induce pIgR expression in tumor cell lines including IL-1 $\beta, T N F \alpha$, IFN $\gamma$, and most recently, IL-17. ${ }^{10,11,22-24,26}$ We wanted to test if primary intestinal epithelial cells responded similarly to these cytokines, and if so, what was the relative potency. To do this, we performed a dose titration using these four cytokines with IgA transcytosis and pIgR expression as readouts (Figure 5). IL-17 was the most potent cytokine tested. A dose of $0.5 \mathrm{ng} \mathrm{ml}^{-1}$ resulted in higher levels of IgA transcytosis than LPS treatment (Figure 5a). IL-1 $\beta$ and TNF $\alpha$ were both significantly less potent than IL-17, as a $100 \mathrm{ng} \mathrm{ml}^{-1}$ dose of these cytokines only induced half the levels of IgA transcytosis as LPS (Figure 5b and $\mathbf{c}$ ). Apical media from pIgR ${ }^{-/-}$cells at all doses of IL- $1 \beta$, TNF $\alpha$, and IL-17 contained no IgA (Figure 5a-c). For all three of these cytokines, the dose-response curves for $\mathrm{pIgR}$ expression mirrored the $\operatorname{IgA}$ transcytosis (Figure 5d-f).

Of note, the results for IFN $\gamma$ treatment were distinct from that of the other cytokines as well as previously published literature using immortalized cell lines (Supplementary Figure 4). At $0.1-1 \mathrm{ng} \mathrm{ml}^{-1}$, the epithelial monolayer did not remain intact, as apical media from wild-type and $\operatorname{IgR}^{-/-}$cells both contained IgA levels similar to the media in the lower compartment (Supplementary Figure 4a).
Furthermore, TER measurements of cytokine-treated cells showed no measureable resistance after IFN $\gamma$ treatment, whereas treatment with IL-1 $\beta$, TNF $\alpha$, and IL-17 showed comparable TER values with LPS-treated cells (Supplementary Figure 4c). At lower doses $\left(0.001-0.01 \mathrm{ng} \mathrm{ml}^{-1}\right)$, less IgA was present in the apical media; however, none of these conditions led to an increase of pIgR mRNA expression (Supplementary Figure 4b). Our conclusion is that IgA uses a paracellular route in IFN $\gamma$-treated cells that could either be due to cell death or leaky junctions.

\section{Colonic epithelial cells generated from $\mathrm{TIr}^{-/-}$mice show reduced IgA transcytosis and plgR expression after LPS but not IL-17 treatment}

One advantage of this system is the ability to isolate cells directly from different genetically modified mice for experiments. As a proof of principle, cells were harvested from $T l r 4^{-/-}$mice to generate colonic spheroids. These cells lack the LPS receptor, Tlr4, and therefore should have a reduced response to LPS stimulation. As expected, IgA transcytosis and pIgR expression was reduced to $\sim 50 \%$ of that of wild-type cells (Figure $6 \mathbf{a}$ and c). The ability of these cells to respond to other stimuli for IgA transcytosis was not affected, as IL-17 treatment of $\mathrm{Tlr} 4^{-1-}$ cells showed no difference from wild-type cells (Figure 6b and $\mathbf{d}$ ).

\section{DISCUSSION}

We have established a new method to grow primary intestinal epithelial cells in a functional monolayer. To do this, we adapted the previously established 3D primary intestinal epithelial stem cell culture system ${ }^{2}$ to a $2 \mathrm{D}$ monolayer in a Transwell. The system we have developed has three important components. Firstly, the use of the L-WRN CM system allowed us to attain large cell numbers that are required to form monolayers in Transwells. Secondly, cells only needed to be grown in Matrigel culture for 3 days before recovery and seeding into Transwells. Lastly, seeded cells quickly formed polarized monolayers and demonstrated high TER values within 3 days. In contrast, previously established intestinal epithelial monolayer systems that utilize immortalized cell lines require as many as 20 days in culture to form differentiated, polarized monolayers. ${ }^{3-5}$

This system will be useful for the study of many different physiologic processes. Here, we chose to focus on IgA transcytosis. For this process to occur, epithelial cells must express the IgA receptor pIgR, which has been shown to be regulated by microbial products. ${ }^{19}$ LPS has been used as a standard in the field to induce pIgR expression in vitro. Typically, immortalized cell lines have been used. Here we showed that LPS-treated primary intestinal epithelial cells were also able to induce $\mathrm{pIgR}$ expression. In addition, we found that maximal pIgR expression required DAPT treatment in addition to LPS, suggesting that the intestinal epithelial cells require differentiation for efficient pIgR expression. To demonstrate the robustness of primary intestinal epithelial cells for IgA transcytosis, we carefully analyzed several key factors including time, IgA dose, 


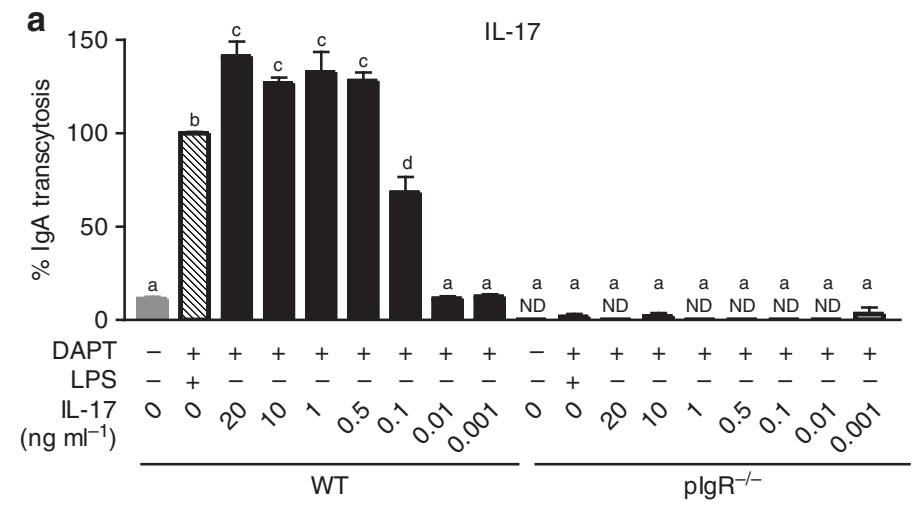

\section{b}

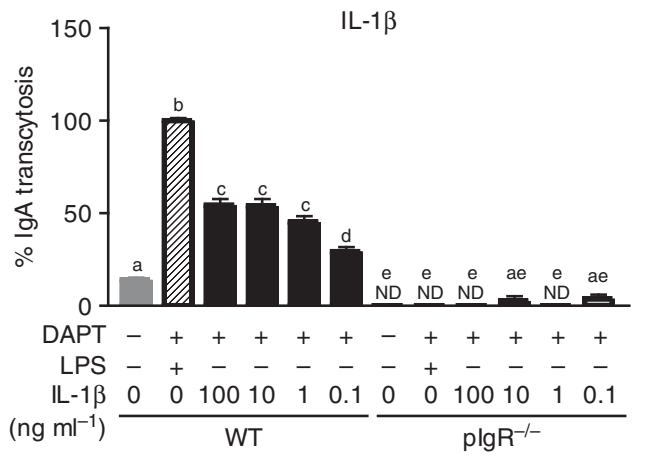

C $150 \quad$ TNF $\alpha$

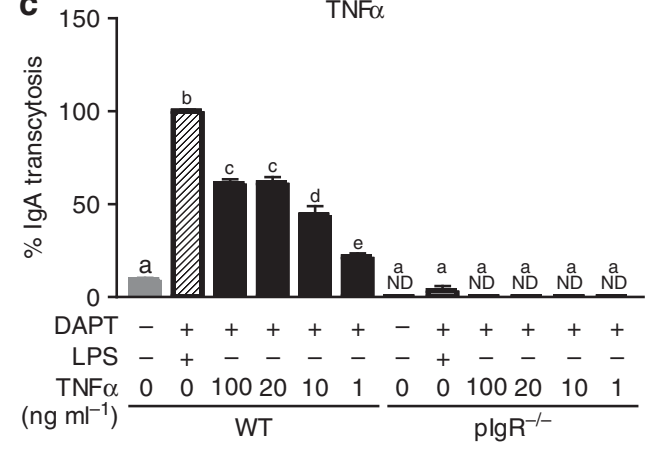

IL-1 $\beta$
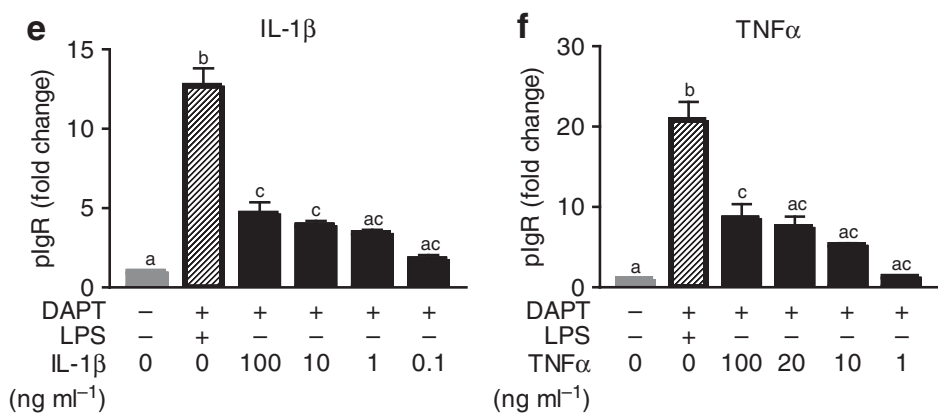

Figure 5 Immunoglobulin A (IgA) transcytosis and polymeric Ig receptor (plgR) expression in response to interleukin (IL)-17, IL-1 $\beta$, and tumor necrosis factor- $\alpha\left(\right.$ TNF $\alpha$ ). Wild-type (WT) and $p l g R^{-} /-$cells were treated with $10 \mu \mathrm{M}$ DAPT $(N-[N-(3,5-$ difluorophenacetyl-L-alanyl)]-S-phenylglycine $t$-butyl ester) and varying doses of (a and $\mathbf{d}) \mathrm{IL}-17$, (b and $\mathbf{e}) \mathrm{IL}-1 \beta$, or (c and $\mathbf{f}) \mathrm{TNF} \alpha$. IgA transcytosis was analyzed by (a-c) enzyme-linked immunosorbent assay (ELISA), and results were normalized to the WT + DAPT + lipopolysaccharide (LPS) group (=100\%). (d-f) Gene expression analysis of plgR was performed, and all samples were normalized to glyceraldehyde 3-phosphate dehydrogenase. Data are presented as fold change relative to untreated $(0 \%$ conditioned media) cells. All values are indicated as mean \pm s.e.m. One-way analysis of variance: $(\mathrm{a}) \mathrm{F}=152.3$, $P<0.0001, n \geq 3$ per group; (b) $F=187.9, P<0.0001, n \geq 3$ per group; (c) $F=376.7, P<0.0001, n \geq 3$ per group; (d) $F=119.5, P<0.0001$, $n \geq 4$ per group; (e) $\mathrm{F}=49.92, P<0.0001, n \geq 5$ per group; and (f) $\mathrm{F}=28.29, P<0.0001, n \geq 4$ per group. Means with different letters are significantly different by Bonferroni's multiple comparison test. ND, not detected.

and LPS dose. We titrated the assay and chose to use $10 \mu \mathrm{m}$ DAPT, $1 \mu \mathrm{g} \mathrm{ml}^{-1}$ LPS, and $50 \mu \mathrm{g} \mathrm{ml}^{-1}$ IgA as our optimal conditions. The time course of a typical experiment is $10 \mathrm{~h}$ with multiple samples taken from each Transwell.

Interestingly, we found that cell density also affected IgA transcytosis. After recovery from the Matrigel, twofold serial dilutions were made before seeding the cells in the Transwells. As it might be expected, we observed a cell density-dependent decrease in the amount of IgA transcytosed. However, this decrease in IgA was not just due to the decrease in cell number. Gene expression analysis of $p I g R$ showed a substantial decrease at the lowest cell densities. Immunofluorescence staining for pIgR correlated with the mRNA expression data, showing fewer
pIgR-positive cells at the lowest cell densities. We hypothesized the lower density cells may be in a less differentiated state, which has been shown in other in vitro cell systems. ${ }^{39-41}$ We therefore tested the expression of other cell differentiation markers, including goblet cell marker Muc2 and a secretory cell lineage marker Atoh 1 , and found both to show a correlation of expression with cell density. This suggests that cell-to-cell endogenous signaling, and not solely exogenous chemical stimuli, regulate colonic cell differentiation in this culture system.

Although LPS robustly induces pIgR expression, it is difficult to translate in vitro quantities to the biomass of intestinal microbes that generate this molecule. To make this system more 
a

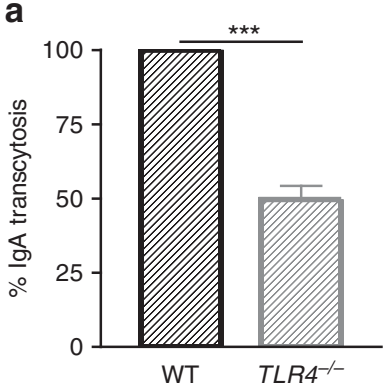

C

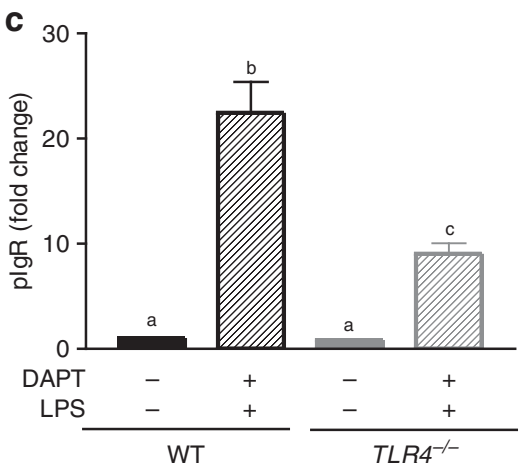

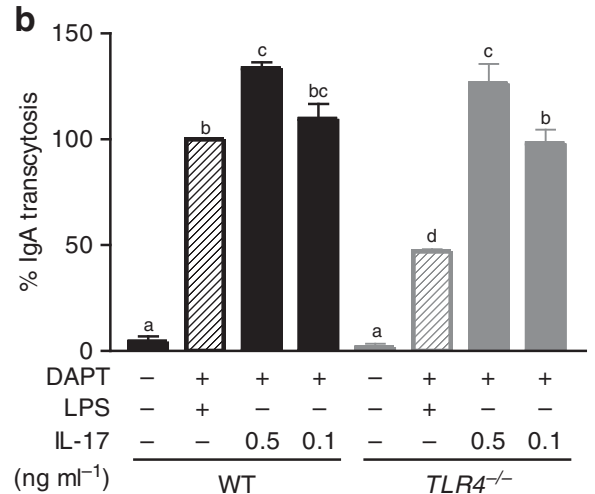

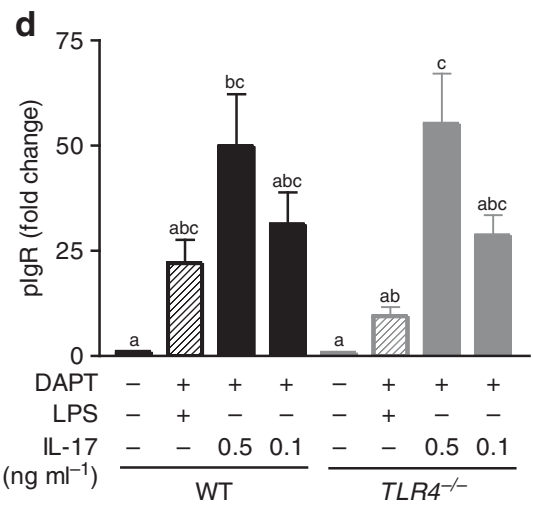

Figure 6 Cells from TIr4 ${ }^{-/-}$mice have an impaired immunoglobulin A (IgA) transcytosis response to lipopolysaccharide (LPS) but not interleukin-17 (IL-17). (a and c) Wild-type (WT) T/r4 and T/r4 ${ }^{-1-}$ were treated with $10 \mu \mathrm{M}$ DAPT ( $N$-[N-(3,5-difluorophenacetyl-L-alanyl)]-S-phenylglycine $t$-butyl ester) and $1 \mu \mathrm{g} \mathrm{ml}^{-1}$ LPS. (a) IgA transcytosis was measured by enzyme-linked immunosorbent assay (ELISA) and results were normalized to the WT group $(=100 \%)$. Values are indicated as mean \pm s.e.m.; $n=8$ per group. Wilcoxon's signed-rank test: ${ }^{* * *} P=0.0039$. (b and d) WT TIr4 and $\mathrm{TIr}^{-1-}$ cells were treated with $10 \mu \mathrm{M}$ DAPT and varying doses of IL-17. (b) IgA transcytosis was analyzed by ELISA and results were normalized to the WT $+\mathrm{D}+\mathrm{L}$ group $(=100 \%)$. (c and d) Gene expression analysis of polymeric Ig receptor (plgR) was performed, and all samples were normalized to glyceraldehyde 3-phosphate dehydrogenase. Data are presented as fold change relative to untreated ( $0 \%$ conditioned media) cells. All values are indicated as mean \pm s.e.m. One-way analysis of variance: (b) $\mathrm{F}=116.9, P<0.0001, n \geq 3$ per group; (c) $\mathrm{F}=40.92, P<0.0001, n \geq 7$ per group; and (d) $F=6.364, P<0.0004, n \geq 3$ per group. Means with different letters are significantly different by Bonferroni's multiple comparison test.

applicable to specific bacteria, we utilized heat-killed bacteria. We therefore treated the cells with heat-killed E. coli and found that a dose of $10^{7}$ colony-forming unit per $\mathrm{ml}$ stimulated $\operatorname{IgA}$ transcytosis and pIgR expression to a similar extent as $1 \mu \mathrm{g} \mathrm{ml}^{-1}$ LPS. We feel that this system will be useful for future studies looking at host-microbial interactions in vitro.

Previous studies found that several host cytokines including IL-1 $\beta, \mathrm{TNF} \alpha$, IFN $\gamma$, and IL-17 have a role in pIgR expression. ${ }^{11,22-26}$ Similar to what has been shown in immortalized cell lines, IL-1 $\beta, \mathrm{TNF} \alpha$, and IL-17 showed a dose-dependent induction of $\mathrm{pIgR}$ expression, with IL-17 being the most potent inducer of $\operatorname{IgA}$ transcytosis and $\mathrm{pIgR}$ expression of these cytokines. However, an important difference we found between our primary mouse intestinal epithelial cells and human cancer cell lines is the ability of IFN $\gamma$ to induce pIgR expression. IFN $\gamma$ treatment did not lead to $\mathrm{pIgR}$ expression or IgA transcytosis at any dose tested, and actually resulted in cell death at higher doses. This may be a result that would otherwise be obscured by using immortalized cell lines, which can be resistant to cytokine-induced cell death. Furthermore, this does not appear to be a species-specific phenomenon, as the mouse promoter for $\mathrm{pIgR}$ is highly conserved to the human promoter and also contains the IRF1 binding site. ${ }^{42}$

One final important advantage of this system is the ability to readily use primary intestinal epithelial cells taken from different genetically modified mice. In this study, we utilized cells obtained from available lines of knockout mice for the $p \operatorname{IgR}$ and Tlr4 genes. Monolayers of epithelial cells derived from these mice allowed us to address directly questions using cells with complete loss of function, as compared with the usual incomplete loss of function with short hairpin RNA knockdowns (i.e. ref. 2).

\section{Prospectus}

In summary, we developed a new system to culture primary intestinal epithelial cells in monolayer culture. Although we have highlighted the capability of this system to be utilized for studies of IgA transcytosis, there are many other experimental avenues where this system should prove to be useful. These areas include barrier function, host-microbial interactions and epithelial-immune/stromal cell interactions. We propose that not only will this system be useful for mechanistic studies but also for large-scale chemical biology screens in these arenas. 


\section{METHODS}

Mice. Animal protocols were approved by the Washington University Animal Studies Committee. All mice were maintained in a specific pathogen-free barrier facility. IgR $^{-/-}$mice (B6.129P2-Pigr ${ }^{\text {tm1Fejo }^{\prime}}$ $\mathrm{Mmmh}^{43}$ ) were initially obtained from Mutant Mouse Regional Resource Center (Columbia, MO). Tlr $4^{-/-}$mice were provided by the laboratory of Dr William F Stenson (B6.B10ScN-TLR4 $4^{\text {lps-del } / J \text { thJ }}$ from Jackson Laboratory, Bar Harbor, $\left.\mathrm{ME}^{44}\right)$. All mice used were 8-10 weeks of age.

3D spheroid cell culture. Primary colonic epithelial stem cells were isolated, grown, and maintained as 3D spheroid cultures in Matrigel (BD Biosciences, San Jose, CA) as described in Miyoshi et al. ${ }^{2}$ Cells were kept in 50\% L-WRN CM. Media were changed every 2 days, and cells were passaged every 3 days (1:3 split).

Formation of Transwell monolayers. To form monolayers of intestinal epithelial cells, spheroids were taken from 3-day-old 3D cultures for plating in Transwells (3413; Corning Costar, Tewksbury, MA). The Transwells were coated in $0.1 \%$ gelatin for $\geq 1 \mathrm{~h}$ at $37^{\circ} \mathrm{C}$. Spheroids were recovered from Matrigel by first washing in a solution of $0.5 \mathrm{~mm}$ EDTA, and then dissociated for $4 \mathrm{~min}$ at $37^{\circ} \mathrm{C}$ using a solution of $0.05 \%$ Trypsin/0.5 mm EDTA. The trypsin was then inactivated using Dulbecco's modified Eagle's medium/F12 media containing 10\% fetal bovine serum. The spheroids were then dissociated by vigorous pipetting (using a 1,000 $\mu$ l pipette). The cells were then passed through a $40 \mu \mathrm{m}$ cell strainer (BD Biosciences) and re-suspended in 50\% L-WRN CM containing $10 \mu \mathrm{M}$ Y-27632 (ROCK inhibitor; Tocris Bioscience and R\&D Systems, Minneapolis, MN). On average, spheroids from three wells of a 24-well plate were plated into the upper compartment of a single Transwell in $100 \mu \mathrm{l}$ of media. An additional $600 \mu \mathrm{l}$ of media were added to the lower compartment of the Transwells.

Cell treatments. On day 1 ( $24 \mathrm{~h}$ after seeding the Transwells), the $50 \%$ L-WRN CM supplemented with Y-27632 was removed and replaced with $0 \% \mathrm{CM}$ (Advanced DMEM/F12 containing 20\% fetal bovine serum, $100 \mathrm{U}$ of penicillin, $0.1 \mathrm{mg} \mathrm{ml}^{-1}$ streptomycin, and $2 \mathrm{~mm} \mathrm{L-glutamine).}$ At this time, any additional treatments were also administered to the cells: LPS (L4391; Sigma, Saint Louis, MO), DAPT $\gamma$-secretase inhibitor (565784; Millipore, Billerica, MA), recombinant mouse IL-1 $\beta$ (R\&D Systems; 401-ML), recombinant mouse IFN $\gamma$ (R\&D Systems; 485-ML), recombinant mouse TNF $\alpha$ (R\&D Systems; 410-MT), recombinant mouse IL-17 (R\&D Systems; 421-ML), and heat-killed E. coli (lab stocks, mouse adapted strain) ${ }^{45}$ Cells were given fresh media with the respective treatments on day 2 , and were treated for a total of $48 \mathrm{~h}$ before being used for IgA transcytosis, histology, or RNA extraction on day 3.

TER measurements. TER was measured for cells in Transwells using an epithelial volt-ohm meter (World Precision Instruments, Sarasota, FL). Resistance of the intestinal epithelial cell monolayer was calculated by subtracting the resistance of the (membrane + media) from the resistance of the (membrane + media + cells). Each Transwell was measured in triplicate and the average value was taken. This value was then multiplied by the area of the Transwell membrane $\left(0.33 \mathrm{~cm}^{2}\right)$ to obtain a final value in $\Omega \mathrm{cm}^{2}$.

IgA transcytosis assay. On day 3 , the Transwells were removed from the various treatment conditions and washed with $0 \% \mathrm{CM}$. A measure of $600 \mu \mathrm{l}$ of $0 \% \mathrm{CM}$ containing mouse IgA (for early studies: sc-3900; Santa Cruz Biotechnology, Dallas, TX; later studies: 553476; BD Pharmingen, San Diego, CA) was added to the lower compartment. Both sources of IgA contained a mixture of monomeric and polymeric IgA, according to each company. For the lot of BD Pharmingen IgA used in these studies, the amount of dimeric IgA was $\sim 85 \%$ according to the manufacturer. A measure of $100 \mu \mathrm{l}$ of $0 \% \mathrm{CM}$ alone was added to the upper compartment and collected at different time points to evaluate the amount of IgA transcytosed by ELISA (E-90A; Immunology Consultants Labs, Portland, OR).
Immunostaining and histologic analysis. Cells in the Transwells were washed with phosphate-buffered saline (PBS) and fixed in either $10 \%$ formalin or Bouins fixative for $10 \mathrm{~min}$. The cells were then washed three times in $70 \%$ ethanol and the Transwell membranes were cut out from the Transwell inserts using a surgical blade. The membranes were processed for paraffin embedding. Five-micron-thick transverse sections were cut for hematoxylin and eosin staining and immunostaining. For this procedure, the sections were deparaffinized, hydrated, boiled in Trilogy solution (Cell Marque, Rocklin, CA) for $20 \mathrm{~min}$, rinsed in PBS, blocked with $1 \%$ bovine serum albumin $/ 0.1 \%$ Triton X-100 for $30 \mathrm{~min}$, and incubated with primary antibody at $4{ }^{\circ} \mathrm{C}$ overnight. Primary antibodies include: rabbit anti-ZO-1 (1:100; Invitrogen/Life Technologies, Grand Island, NY), mouse anti-chicken Villin1 (1:100; AbDSerotec, Raleigh, NC), and goat anti-pIgR (1:500; R\&D Systems). The slides were rinsed three times in PBS and then incubated with AlexaFluor594- or AlexaFluor488-conjugaed speciesspecific secondary antibodies for $1 \mathrm{~h}$ at room temperature (1:500; Invitrogen/Life Technologies). Slides were washed three times in PBS and stained with bis-benzimide (Hoescht 33258; Invitrogen/Life Technologies) to visualize nuclei and mounted with a 1:1 PBS-glycerol solution. Staining was visualized with a Zeiss (Oberkochen, Germany) Axiovert 200 microscope with an Axiocam MRM digital camera.

For whole mount immunostaining, cells were fixed and washed in the Transwells as described above, and then washed three times with PBS before they were cut out from the Transwell inserts and placed in the wells of a 24 -well plate. The membranes were then blocked and stained as described above. Nuclei counts were made using ImageJ (Bethesda, MD). ${ }^{46}$

For whole tissue immunostaining, mouse colons were harvested and prepared as described previously. ${ }^{4}$

Gene expression analysis. RNA was isolated from cells in the Transwells on day 3 after seeding using the NucleoSpin RNA II isolation kit (Macherey-Nagel, Bethlehem, PA). Complementary DNA synthesis was performed using $0.2 \mu \mathrm{g}$ of RNA and the SuperScript III reverse transcriptase (Life Technologies). Quantitative polymerase chain reaction reactions were performed with SYBR Advantage qPCR Premix (Clontech, Mountain View, CA). Expression levels were determined in triplicate per sample and normalized to the expression of glyceraldehyde 3-phosphate dehydrogenase. Primers used include: glyceraldehyde 3-phosphate dehydrogenase for, 5' -AGGTCGGTGTG AACGGATTTG-3', glyceraldehyde 3-phosphate dehydrogenase rev, 5'-TGTAGACCATGTAGTTGAGGTCA-3'; pIgR for, 5' ${ }^{\prime}$-ATGAGG CTCTACTTGTTCACGC-3', pIgR rev, $5^{\prime}$-CGCCTTCTATACTAC TCACCTCC- $3^{\prime}$; Villin 1 for, $5^{\prime}$-ATGACTCCAGCTGCCTTCTCT-3', Villin1 rev, $5^{\prime}$-GCTCTGGGTTAGAGCTGTAAG-3'; Reg3g for, 5'-C ATCAACTGGGAGACGAATCC-3', Reg3g rev, 5' -CAGAAATCCT GAGGCTCTTGACA-3'; Muc2 for, 5' -ATGCCCACCTCCTCAAAG AC-3', Muc2 rev, 5'-GTAGTTTCCGTTGGAACAGTGAA- $3^{\prime}$; and Atoh 1 for, $5^{\prime}$-GAGTGGGCTGAGGTAAAAGAGT-3' and Atoh1 rev, 5'-GGTCGGTGCTATCCAGGAG-3'.

SUPPLEMENTARY MATERIAL is linked to the online version of the paper at http://www.nature.com/mi

\section{ACKNOWLEDGMENTS}

We thank Gerard E. Kaiko for comments on the manuscript. This work was supported by Al08488702, the CCFA Genetics initiative, and the Helmsley Charitable Trust. C.M. and K.L.V. were supported by an NIH training grant (T32 Al007163). The Washington University Digestive Disease Research Core Center is supported by a grant from the National Institute of Diabetes and Digestive and Kidney Disease (NIDDK) (P30DK052574).

\section{DISCLOSURE}

The authors declare no conflict of interest.

(c) 2014 Society for Mucosal Immunology 


\section{REFERENCES}

1. Sato, T. et al. Single Lgr5 stem cells build crypt-villus structures in vitro without a mesenchymal niche. Nature 459, 262-265 (2009).

2. Miyoshi, H., Ajima, R., Luo, C.T., Yamaguchi, T.P. \& Stappenbeck, T.S. Wnt5a potentiates TGF-beta signaling to promote colonic crypt regeneration after tissue injury. Science 338, 108-113 (2012).

3. Sambuy, Y. et al. The Caco-2 cell line as a model of the intestinal barrier: influence of cell and culture-related factors on Caco-2 cell functional characteristics. Cell Biol. Toxicol. 21, 1-26 (2005).

4. Meunier, V., Bourrie, M., Berger, Y. \& Fabre, G. The human intestinal epithelial cell line Caco-2; pharmacological and pharmacokinetic applications. Cell Biol. Toxicol. 11, 187-194 (1995).

5. Rousset, M. The human colon carcinoma cell lines HT-29 and Caco-2: two in vitro models for the study of intestinal differentiation. Biochimie 68 , 1035-1040 (1986).

6. Duizer, E., Penninks, A.H., Stenhuis, W.H. \& Groten, J.P. Comparison of permeability characteristics of the human colonic Caco-2 and rat small intestinal IEC-18 cell lines. J. Control Rel. 49, 39-49 (1997).

7. Irvine, J.D. et al. MDCK (Madin-Darby canine kidney) cells: a tool for membrane permeability screening. J. Pharm. Sci. 88, 28-33 (1999).

8. Kuratnik, A. \& Giardina, C. Intestinal organoids as tissue surrogates for toxicological and pharmacological studies. Biochem. Pharmacol. 85 1721-1726 (2013)

9. Sun, H., Chow, E.C.Y., Liu, S., Du, Y. \& Pang, K.S. The Caco-2 cell monolayer: usefulness and limitations. Expert Opin. Drug Metab. 4, 395-411 (2008).

10. Kaetzel, C.S. The polymeric immunoglobulin receptor: bridging innate and adaptive immune responses at mucosal surfaces. Immunol. Rev. 206, 83-99 (2005).

11. Johansen, F.E. \& Kaetzel, C.S. Regulation of the polymeric immunoglobulin receptor and IgA transport: new advances in environmental factors that stimulate plgR expression and its role in mucosal immunity. Mucosal Immunol. 4, 598-602 (2011).

12. Rojas, R. \& Apodaca, G. Immunoglobulin transport across polarized epithelial cells. Nat. Rev. Mol. Cell. Biol. 3, 944-955 (2002).

13. Hooper, L.V. OPINION Do symbiotic bacteria subvert host immunity? Nat. Rev. Microbiol. 7, 367-374 (2009).

14. Hamburger, A.E., Bjorkman, P.J. \& Herr, A.B. Structural insights into antibody-mediated mucosal immunity. Curr. Top. Microbiol. Immunol. 308 , 173-204 (2006).

15. Brandtzaeg, P. \& Prydz, H. Direct evidence for an integrated function of $J$ chain and secretory component in epithelial transport of immunoglobulins. Nature 311, 71-73 (1984).

16. Mostov, K.E., Kraehenbuhl, J.P. \& Blobel, G. Receptor-mediated transcellular transport of immunoglobulin: synthesis of secretory component as multiple and larger transmembrane forms. Proc. Natl. Acad. Sci. USA 77 7257-7261 (1980)

17. Mostov, K.E., Verges, M. \& Altschuler, Y. Membrane traffic in polarized epithelial cells. Curr. Opin. Cell Biol. 12, 483-490 (2000).

18. Lindh, E. Increased resistance of immunoglobulin a dimers to proteolytic degradation after binding of secretory component. J. Immunol. 114, 284-286 (1975).

19. Hooper, L.V. et al. Molecular analysis of commensal host-microbial relationships in the intestine. Science 291, 881-884 (2001).

20. Bruno, M.E. et al. Regulation of the polymeric immunoglobulin receptor in intestinal epithelial cells by Enterobacteriaceae: implications for mucosal homeostasis. Immunol. Invest. 39, 356-382 (2010).

21. Schneeman, T.A. et al. Regulation of the polymeric lg receptor by signaling through TLRs 3 and 4: linking innate and adaptive immune responses. J. Immunol. 175, 376-384 (2005).

22. Blanch, V.J., Piskurich, J.F. \& Kaetzel, C.S. Cutting edge: coordinate regulation of IFN regulatory factor-1 and the polymeric Ig receptor by proinflammatory cytokines. J. Immunol. 162, 1232-1235 (1999).

23. Piskurich, J.F. et al. Transcriptional regulation of the human polymeric immunoglobulin receptor gene by interferon-gamma. Mol. Immunol. 34, 75-91 (1997).

24. Schjerven, H., Brandtzaeg, P. \& Johansen, F.E. A novel NF-kappa B/Rel site in intron 1 cooperates with proximal promoter elements to mediate TNF-alpha-induced transcription of the human polymeric lg receptor. J. Immunol. 167, 6412-6420 (2001).
25. Hayashi, M. et al. The polymeric immunoglobulin receptor (secretory component) in a human intestinal epithelial cell line is up-regulated by interleukin-1. Immunology 92, 220-225 (1997).

26. Cao, A.T., Yao, S., Gong, B., Elson, C.O. \& Cong, Y. Th17 cells upregulate polymeric lg receptor and intestinal $\lg A$ and contribute to intestinal homeostasis. J. Immunol. 189, 4666-4673 (2012).

27. VanDussen, K.L. et al. Notch signaling modulates proliferation and differentiation of intestinal crypt base columnar stem cells. Development 139, 488-497 (2012)

28. van Es, J.H. et al. Notch/gamma-secretase inhibition turns proliferative cells in intestinal crypts and adenomas into goblet cells. Nature 435, 959-963 (2005).

29. Bretscher, A. \& Weber, K. Villin: the major microfilament-associated protein of the intestinal microvillus. Proc. Natl. Acad. Sci. USA 76, 2321-2325 (1979).

30. Stevenson, B.R., Siliciano, J.D., Mooseker, M.S. \& Goodenough, D.A. Identification of ZO-1: a high molecular weight polypeptide associated with the tight junction (zonula occludens) in a variety of epithelia. J. Cell Biol. 103, 755-766 (1986)

31. O'Connor, D.T., Burton, D. \& Deftos, L.J. Chromogranin A: immunohistology reveals its universal occurrence in normal polypeptide hormone producing endocrine glands. Life Sci. 33, 1657-1663 (1983).

32. Falk, P., Roth, K.A. \& Gordon, J.I. Lectins are sensitive tools for defining the differentiation programs of mouse gut epithelial cell lineages. Am. J. Physiol. 266, G987-1003 (1994).

33. Cash, H.L., Whitham, C.V., Behrendt, C.L. \& Hooper, L.V. Symbiotic bacteria direct expression of an intestinal bactericidal lectin. Science 313, 1126-1130 (2006).

34. Maunoury, R. et al. Villin expression in the visceral endoderm and in the gut anlage during early mouse embryogenesis. EMBO J 7, 3321-3329 (1988).

35. Song, W., Bomsel, M., Casanova, J., Vaerman, J.P. \& Mostov, K. Stimulation of transcytosis of the polymeric immunoglobulin receptor by dimeric IgA. Proc. Natl. Acad. Sci. USA 91, 163-166 (1994).

36. Diebel, L.N. \& Liberati, D.M. Disparate effects of bacteria and Toll-like receptor-dependant bacterial ligand stimulation on immunoglobulin $A$ transcytosis. J. Trauma 70, 691-700 (2011).

37. Frantz, A.L. et al. Targeted deletion of MyD88 in intestinal epithelial cells results in compromised antibacterial immunity associated with downregulation of polymeric immunoglobulin receptor, mucin-2, and antibacterial peptides. Mucosal Immunol. 5, 501-512 (2012).

38. Nakamura, Y. et al. Upregulation of polymeric immunoglobulin receptor expression by the heat-inactivated potential probiotic Bifidobacterium bifidum OLB6378 in a Mouse Intestinal Explant Model. Scand. J. Immunol. 75, 176-183 (2012).

39. Ezeonu, I., Wang, M., Kumar, R. \& Dutt, K. Density-dependent differentiation in nontransformed human retinal progenitor cells in response to basic fibroblast growth factor- and transforming growth factor-alpha. DNA Cell Biol. 22, 607-620 (2003).

40. Lee, Y.S., Yuspa, S.H. \& Dlugosz, A.A. Differentiation of cultured human epidermal keratinocytes at high cell densities is mediated by endogenous activation of the protein kinase $\mathrm{C}$ signaling pathway. J. Invest. Dermatol. 111, 762-766 (1998)

41. McBeath, R., Pirone, D.M., Nelson, C.M., Bhadriraju, K. \& Chen, C.S. Cell shape, cytoskeletal tension, and RhoA regulate stem cell lineage commitment. Dev. Cell 6, 483-495 (2004).

42. Mestecky, J. et al. Mucosal Immunology. (Academic Press, San Diego, CA, 2005)

43. Johansen, F.E. et al. Absence of epithelial immunoglobulin A transport, with increased mucosal leakiness, in polymeric immunoglobulin receptor/ secretory component-deficient mice. J. Exp. Med. 190, 915-921 (1999).

44. Poltorak, A. et al. Defective LPS signaling in $\mathrm{C} 3 \mathrm{H} / \mathrm{HeJ}$ and $\mathrm{C} 57 \mathrm{BL} / 10 \mathrm{ScCr}$ mice: mutations in Tir4 gene. Science 282, 2085-2088 (1998).

45. Bloom, S.M. et al. Commensal Bacteroides species induce colitis in host-genotype-specific fashion in a mouse model of inflammatory bowel disease. Cell Host Microbe 9, 390-403 (2011).

46. Schneider, C.A., Rasband, W.S. \& Eliceiri, K.W. NIH Image to ImageJ: 25 years of image analysis. Nat. Methods 9, 671-675 (2012).

47. Kang, S.S. et al. An antibiotic-responsive mouse model of fulminant ulcerative colitis. PLoS Med. 5, e41 (2008) 